\title{
Jérôme Bimbenet, Film et histoire
}

Paris, A. Colin, coll. U. Histoire contemporaine, 2007, 286 p.

\section{Marie Louis}

\section{CpenEdition}

\section{Journals}

Édition électronique

URL : http://journals.openedition.org/questionsdecommunication/1276

DOI : 10.4000/questionsdecommunication. 1276

ISSN : 2259-8901

\section{Éditeur}

Presses universitaires de Lorraine

\section{Édition imprimée}

Date de publication : 1 décembre 2008

Pagination : 314-315

ISBN : 978-2-86480-981-4

ISSN : 1633-5961

\section{Référence électronique}

Marie Louis, « Jérôme Bimbenet, Film et histoire », Questions de communication [En ligne], 14 | 2008, mis en ligne le 19 janvier 2012, consulté le 22 septembre 2020. URL : http://journals.openedition.org/ questionsdecommunication/1276; DOI : https://doi.org/10.4000/questionsdecommunication.1276

Ce document a été généré automatiquement le 22 septembre 2020.

Tous droits réservés 


\title{
Jérôme Bimbenet, Film et histoire
}

Paris, A. Colin, coll. U. Histoire contemporaine, 2007, 286 p.

\author{
Marie Louis
}

\section{RÉFÉRENCE}

Jérôme Bimbenet, Film et histoire, Paris, A. Colin, coll. U. Histoire contemporaine, 2007, $286 \mathrm{p}$.

1 À l'époque du tout image où ce qui n'est pas vu n'existe pas, il est bon de s'arrêter sur le lien entre image et pouvoir. Il est bon aussi de regarder de plus près le rôle propagandiste des images tout au long de l'histoire. C'est ce que propose Jérôme Bimbenet dans un ouvrage à visée pédagogique. La première partie, " De la représentation du pouvoir au cinéma de propagande » (pp. 7-148), est consacrée à une définition critique et historique des concepts qui constituent cette étude. Nombreuses sont les mises en garde contre l'apparente objectivité des images et le contrôle que le pouvoir peut exercer sur elles. Mais ce sont plus particulièrement quatre périodes et/ ou thèmes

2 que l'auteur retient : celle de l'édification où l'on marque une présence physique et morale en laissant un patrimoine immobilier. La période pharaonique est ici exemplaire ; la propagation où l'on fait passer son message au plus grand nombre. De ce point de vue, la création de la congrégation de la propaganda fidei par l'Église catholique en réponse à la Réforme protestante est largement traitée ; la persuasion qui consiste à légitimer des idées via des rites ou symboles. Sous cet angle, la Révolution française a largement contribué à crédibiliser les idées révolutionnaires en leur donnant un texte fondateur, des martyrs, des rites; la grande diffusion où tous les moyens disponibles sont utilisés pour occuper physiquement ou idéologiquement le terrain. La Première Guerre mondiale a initié ce phénomène. Pour chacun de ces cas, l'auteur s'attache à mettre en lumière ce qui se cache derrière des images souvent considérées souvent anodines, car celles-ci sont « une projection de la réalité, qui se veut aussi ressemblante que possible à celle-ci ; elle[s] appara[issent] comme une simili- 
réalité mais devien[nent] par extrapolation (extrapolarisation) une hypervérité, audelà de la vérité: une méta-réalité» (p. 11).

Dès l'introduction, le ton est donné : tout ce qui s'apparente au cinéma - la représentation, la photographie, le cinéma en tant que tel, la culture de masse- connaît le même traitement. Le chercheur rappelle qu'une représentation n'est jamais innocente dès lors qu'elle participe à la formation d'une identité culturelle et sociale. Pour mieux cerner ce qu'est le cinéma, Jérôme Bimbenet revient sur les apports de la photographie. En fixant un moment donné, celle-ci pose le problème de la force de crédibilité de ce support, par exemple en comparaison à la peinture. En dépassant la fixité, le cinéma accentue ce phénomène. Pourtant, dès les premiers films, un langage s'instaure pour contourner cette réalité et créer des œuvres plus vraisemblables que vrai. La médiation artistique rendrait-elle un événement plus imposant, plus influent ? Il semblerait que oui, et cela notamment grâce à l'impact du cinéma sur les foules. D'abord, celui-ci ne s'adresse pas à la raison, mais à l'affect. L'auteur fait appel au concept de l'« être ensemble anonyme ", mis au point par Gabriella Turnaturi ("Les métamorphoses du divertissement citadin dans l'Italie unifiée - 1870-1915 ", pp. 171-190, in : Alain Corbin, dir., L'avènement des loisirs 1850-1960, Paris, Aubier, 1995). Dans une salle de cinéma, chacun vit ses émotions séparément, comme si le film lui parlait directement. Néanmoins, cette réception étant collective, c'est ensemble que le groupe réagit individuellement. Le film communique donc autant avec la masse qu'avec l'individu. Ainsi le cinéma devient-il une culture de masse avec tout ce que cela comporte : fascination dangereuse pour un monde illusoire, perception réductrice et manichéenne pour plaire au plus grand nombre, passivité de la réception, création d'une nouvelle culture: « Le cinéma apprend la vie, il apprend à aimer, à embrasser, il modélise le héros et impose ses rites et ses mythes. Il développe un processus d'identification à des valeurs communes » (p. 127).

La deuxième partie, "Les totalitarismes et l'Amérique face au cinéma de propagande " (pp. 149-259), illustre ce phénomène à travers plusieurs exemples : la Révolution russe, l'Italie fasciste, l'Allemagne nazie et les États-Unis. Des différences apparaissent quant à l'implication de l'État qui ne dispose n'a pas forcément des mêmes pouvoirs. Par exemple, en Italie, une grande liberté était laissée aux cinéastes, et en Union soviétique, au début de la Révolution, le cinéma se révèle être un médium élitiste, intellectuel. D'ailleurs, les réalisateurs de cette époque ont inventé et théorisé un langage cinématographique novateur et esthétique. Quant au cinéma nazi, il se devait d'être immédiatement accessible. D'où son caractère plus figuratif. Les genres privilégiés par chacun de ces régimes divergent donc. L'Italie mussolinienne se tourne résolument vers des fictions, tandis que les grands films de propagande allemands sont des documentaires. Mais ces distinctions sont loin d'occulter des points communs, dont le plus notable est la propagande. Si les États-Unis ne sont pas un pays totalitaire l'auteur le rappelle -, mais la force du pouvoir économique et culturelle de ce pays apparente la large diffusion du modèle étatsunien à de la propagande.

5 Pour diffuser leurs idées, les quatre régimes cités ont pleinement utilisé les possibilités du langage cinématographique. Dans quelques films, bien que le fond soit en tout point détestable, la forme y est souvent remarquable. Ainsi Le Cuirassé Potemkine (Eisenstein, 1927), Cabiria (Pastrone, 1914), Le Triomphe de la Volonté (Riefenstahl, 1933), Naissance d'une Nation (Griffith, 1914) ont-ils durablement influencé l'histoire du cinéma. On leur doit l'invention du travelling, l'importance du montage, l'utilisation pertinente du 
cadre, de la musique... Par ailleurs, tous utilisent les principes de la propagande tels que définis en conclusion: « La règle de la simplification et d'ennemi unique, [...] la règle de grossissement et de défiguration, [...] la règle d'orchestration, [...] la règle de transfusion : récupération d'un passé mythique, [...] la règle d'unanimité et de contagion » (p. 264).

6 Cette reprise des éléments importants en conclusion ou à l'intérieur même des chapitres est un élément clé de cet ouvrage très bien structuré. Jérôme Bimbenet a soigné ses transitions et conclusions intermédiaires ; il accompagne le lecteur et s'assure que ce dernier ne se perd pas dans les méandres de ses 300 pages. En outre, quand la contextualisation semble éloignée du sujet - n'oublions pas que Jérôme Bimbenet commence son historique avec les œuvres pariétales - il s'emploie à relier les arguments et exemples qu'il avance. Ainsi en est-il de l'exemple des hommes des cavernes dont l'auteur montre que leurs représentations des scènes de chasse ritualisent un moment important pour le groupe. Le rappel d'action héroïque n'est-il pas un des principes de la propagande?

7 Pour convaincre, l'auteur peut compter sur sa plume efficace, caustique et amusante par endroit. Cette dernière ferait presque oublier l'utilisation trop évidente du " copier/coller ». Il faut avouer que relire mot pour mot la même phrase en plusieurs endroits du texte entache quelque peu ce bel ouvrage pédagogique. Il en va ainsi des conseils, pourtant fort judicieux, donnés par Jérôme Bimbenet pour utiliser certains films à même d'illustrer une époque, ou des images particulières pour illustrer un cours sur la propagande. La mise en garde est constante et ce, jusqu'à la conclusion :« Apprendreà lire les images, à décrypter les films, à connaître le langage cinématographique et ses significations, c'est permettre l'apprentissage du libre arbitre sans lequel il ne peut y avoir de citoyens libres » (p. 265).

\section{AUTEURS}

\section{MARIE LOUIS}

CREM, Université Paul Verlaine-Metz, louis.marie.82@voila.fr 